\title{
Voikukan vaikutus säilörehun säilöntälaatuun ja rehuarvoihin
}

Terhi Rahkonen ja Elina Juutinen

Maa- ja elintarviketalouden tutkimuskeskus, Kotieläintuotannon tutkimus, Halolantie 31A, 71750 Maaninka,terhirahkonen@hotmail.com,elina.juutinen@mtt.fi

\section{Tiivistelmä}

Voikukka on yleinen rikkakasvi säilörehunurmipelloilla ja etenkin vanhoilla nurmilla (Kajan ja Nousiainen 2006). Syväjuurinen voikukka levittäytyy nopeasti nurmen aukkopaikkoihin vieden valoa, vettä ja ravinteita nurmikasveilta.

Karjatilan kannattava peltoviljely-hanke järjesti kesällä 2010 MTT Maaningalla timoteivoikukka-minisiilokokeen. Minisiilokokeen tavoitteena oli selvittää, kuinka eri voikukkapitoisuudet $(0,25,50,75$ ja $100 \%$ tuorepainosta) vaikuttavat timoteisäilörehun säilönnälliseen laatuun, kemialliseen koostumukseen ja rehuarvoihin ensimmäisessä sadossa. Timotein ja voikukan raaka-ainenäytteet sekä siilojen säilörehut analysoitiin 90 päivän säilönnän jälkeen. Minisiilokokeen tuloksia verrattiin muihin ulkomaalaisiin voikukasta tehtyihin tutkimustuloksiin ja kirjallisuuteen sekä lypsylehmien hyvän nurmisäilörehun laatu- ja ruokintasuosituksiin.

Samaan aikaan korjatun voikukan ja timotein D-arvot olivat varsin samanlaisia (erotus $27 \mathrm{~g} / \mathrm{kg}$ ka). Voikukkapitoisen säilörehun NDF-pitoisuus oli huomattavasti timotei-säilörehua alhaisempi (310 vs. $557 \mathrm{~g} / \mathrm{kg} \mathrm{ka}$ ). Voikukkaa sisältävässä säilörehussa etenkin kaliumin, magnesiumin ja kalsiumin määrät lisääntyivät. Kuitenkin ekvivalenttisuhteena laskettuna voikukan sisältämän kaliumin suhde kalsiumin ja magnesiumin yhteismäärään oli pienempi kuin timotein.

Tässä kokeessa kaikkien koesiilojen pH laski alle 4. Voikukka ei vaikuttanut säilönnän aikana haihtuvien rasvahappojen eikä sokereiden määrään. Liukoisen typen osuus kokonaistypestä pieneni, kun voikukan määrä lisääntyi säilörehussa. Kaikissa koesiiloissa liukoisen typen määrät ylittivät hyvän säilörehun suositusarvon. Voikukan määrän muuttuessa ainoastaan ammoniumtypen osuus kokonaistypen määrästä ei muuttunut systemaattisesti. Tämän kokeen ja kirjallisuuden perusteella voidaan olettaa, että voikukkapitoisesta nurmesta voidaan saada säilöntälaadultaan laadukasta rehua, ja ettei voikukan nurmea korkeampi puskurikapasiteetti ole ongelma etenkään, jos säilönnän onnistumisen muut edellytykset ovat kunnossa.

Voikukan pienempi kuiva-ainepitoisuus verrattuna timoteihin voi lisätä säilörehun puristenestemäärää. Pelkän timoteisäilörehun kuiva-ainepitoisuus oli $329 \mathrm{~g} / \mathrm{kg}$ ja puhtaan voikukkasäilörehun $156 \mathrm{~g} / \mathrm{kg}$, kun niiden esikuivatusaika oli sama. Jos voikukkapitoisen säilörehun esikuivatusaikaa ei lisätä, kuiva-ainepitoisuus jää matalaksi ja puristenesteen määrä lisääntyy. Tässä artikkelissa ei oteta kantaa vaikutuksiin, joita voikukalla voi olla nurmen satotasoon.

Asiasanat: voikukat, Taraxacum spp., timotei, Phleum pratense, nurmiheinät, säilörehu, puskurikapasiteetti, käyminen, rehuarvo, kivennäisaineet 


\section{Johdanto}

Toukokuussa 2011 Suomessa oli noin 914000 nautaa (Tike 2011a). ProAgrian tilastojen mukaan ProTuotos lehmien ruokinnasta 47,5 \%:a kuiva-aineesta perustui säilörehuun vuonna 2010 (Huhtamäki 2011). Vuonna 2011 nurmien osuus maatalousmaasta oli 29,1\%, josta suurin osa, 582300 hehtaaria, oli rehunurmena (Tike 2011b).

Voikukka on yleinen monivuotinen rikkakasvi säilörehunurmipelloilla. Syväjuurinen voikukka kuluttaa nurmikasveilta vettä ja ravinteita sekä kasvutilaa ja valoa levittäytymällä nurmikasvuston aukkopaikkoihin. Voikukan määrän kehittymisestä nurmiviljelyssä ei ole tehty tutkimuksia Suomessa. Voikukan uskotaan lisäävän nurmen sato- ja laatutappioita ja sen väitetään heikentävän säilörehun säilyvyyttä ja aiheuttavan makuvirheitä maitoon. Vanhoissa ruotsalaislähteissä (Gummesson 1987 ja Spörndly 1989) ei voikukkaa ole listattu myrkyllisten eikä maidonlaatua heikentävien kasvien listalle eikä tuoreempaa tietoa asiasta löydetty. Lisäksi voikukan ja muidenkin rikkakasvien vaikutuksista säilörehun säilönnälliseen laatuun on tutkittu yllättävän vähän. Suomessa ei ole tehty säilörehukokeita, jotka olisivat sisältäneet voikukkaa. Ulkomailla on sitä vastoin tehty jonkin verran sekä säilöntä- että korjuuaikakokeita, joissa voikukka on ollut mukana. Näiden tutkimustuloksien vertailu on kuitenkin hankalaa, koska korjattujen säilörehujen nurmikasvit eivät ole samoja kuin Suomessa ja lisäksi koejärjestelyiden välillä on paljon eroja.

Voikukalla on erilainen kivennäissisältö kuin nurmikasveilla. Voikukka sisältää enemmän kalsiumia, kaliumia ja magnesiumia kuin timotei. Yleinen käsitys on, että voikukka lisää poikimahalvausriskiä, koska siinä on paljon kaliumia. Kuitenkin kaliumin suhde magnesiumin ja kalsiumin kokonaismäärään ekvivalentteina laskettuna on ollut hyvä. Kivennäistasapaino on tärkein tekijä poikimahalvauksen ennaltaehkäisyssä. Poikimahalvausriski voi kasvaa, jos lehmä saa ummessaolokaudella kalsiumia suhteessa enemmän kuin magnesiumia. Liika kalium rehussa estää pötsissä magnesiumin imeytymisen lehmän elimistöön ja voi johtaa hypomagnesemiaan.

Voikukka on eronnut useimmissa kokeissa rehuarvoiltaan ja kemialliselta koostumukseltaan nurmiheinistä, mutta siihen on vaikuttanut myös voikukan kehitysaste. Aikaisemmissa kokeissa voikukan energia-arvo oli englanninraiheinään verrattuna pienempi kuin samaan aikaan korjatun nurmen (Mainz 1995, Isseltein 1993). Raakavalkuaispitoisuus oli sitä vastoin suurempi kuin nurmiheinillä (Harrington ym. 2006, Isseltein 1993). Isselteinin ja Danielin (1996) mukaan myös niittokerta on vaikuttanut raakavalkuaisen ja sokereiden pitoisuuteen siten, että keväällä pitoisuus on pienempi kuin kesällä. Voikukan NDF-pitoisuus oli pienempi kuin nurmisäilörehussa (Harrington ym. 2006, Wyss ja Vogel 1994).

Voikukalla on arveltu olevan heikompi säilöntälaatu nurmisäilörehuun verrattuna, koska voikukan puskurikapasiteetti on ollut suurempi (McDonald 1991, Isseltein \& Daniel 1996). Molemmissa Isselsteinin ja Danielin $(1996,1993)$ kokeissa todettiin, että voikukan korkea puskurikapasiteetti ei kuitenkaan heikennä rehun käymislaatua. Voikukkavaltaisessa säilörehussa oli ollut enemmän sokereita ja käyminen intensiivisempää (Wyss \& Vogel 1994) sekä maitohappoa oli syntynyt runsaammin erityisesti keväällä korjatussa voikukkapitoisessa rehussa verrattuna nurmisäilörehuun (Isseltein \& Daniel 1996). Lisäksi voikukkapitoisessa säilörehussa haihtuvien rasvahappojen määrät ovat olleet pienemmät verrattuna nurmisäilörehuun (Wyss \& Vogel 1994), vaikkakin joskus myös suuremmat, erityisesti voihapon osalta (Isseltein \& Daniel 1996).

Säilörehukoe tehtiin MTT:n ja Maito-Savon Karjatilan kannattava peltoviljely -hankkeessa (KARPE), jonka tavoitteena on nurmi- ja säilörehutuotannon kehittäminen pohjoissavolaisilla ja pohjoispohjalaisilla tiloilla. Hankkeen rahoittajana toimivat Pohjois-Savon ja Pohjois-Pohjanmaan elinkeino-, liikenne- ja ympäristökeskukset (Euroopan maaseuturahasto). Yksi keskeisistä hankkeen tavoitteista on nurmien rikkakasvitorjunnan kynnysarvojen tarkentaminen, johon kuuluu rikkakasvien haittavaikutuksien arviointi säilörehussa. Tutkimuksen tavoitteena oli selvittää, miten voikukka vaikuttaa säilörehun säilymislaatuun, kemialliseen koostumukseen ja rehuarvoihin kirjallisuuden ja minisiilokokeen perusteella. 


\section{Aineisto ja menetelmät}

Kirjallisuusselvityksen lisäksi työssä käytetään MTT Maaningan tutkimusasemalla kesällä 2010 tehdyn minisiilokokeen tuloksia. Koekasveina olivat timotei (Phleum pratense) ja voikukka (Taraxacum officinale), jotka niitettiin ensimmäisen säilörehunkorjuun aikaan 15.6.2010. Timotei ja voikukka otettiin vuonna 2004 perustetulta koeruuduilta, jotka olivat saaneet satovuonna ensimmäisen lannoituksen 5.5.2010, josta tuli $100 \mathrm{~kg}$ typpeä, $15 \mathrm{~kg}$ fosforia ja $45 \mathrm{~kg}$ kaliumia hehtaarille. Niittohetkellä voikukka oli kehitysasteen lopulla ja siitä suurin osa levitti siementä.

Minisiilot olivat 130 millilitran kokoisia pieniä lasisia pulloja. Säilöntään käytettiin AIV®2 plus-liuosta (Kemira Oyj). Timoteistä ja voikukasta tehtiin viisi eri seosta, joista jokaista oli kolme toistoa. Seossuhteet olivat 100/0, 75/25, 50/50, 25/75 ja 0/100, joista ensimmäinen luku on timotein, ja jälkimmäinen luku voikukan tuorepainon prosentuaalinen osuus seoksesta. Timotei- ja voikukkanäytteet silputtiin laboratoriosilppurilla noin $2-5 \mathrm{~cm}$ pitkäksi. Voikukkasilppu sisälsi voikukan lehtiä, kukkavarsia ja kukintoja.

Silputtuja rehuja esikuivatettiin ensiksi kuusi tuntia pöydälle levitettynä. Molemmat kasvit kuivattiin omissa noin senttimetrin paksuisissa kasoissa välillä käännellen, jotta saatiin mahdollisimman tasainen kuivuminen. Esikuivatuksen jälkeen rehukasat odottivat yön yli yhdeksän tuntia muovien alla. Rehut peitettiin muovilla, jottei rehu kuivuisi liikaa. Aamulla otettiin yhdet raaka-ainenäytteet pakastimeen molemmista kasoista, puhtaasta timoteista ja voikukasta, jonka jälkeen molempiin kasoihin ruiskutettiin AIV®2 Plus-liuosta suihkepullolla kasoja koko ajan käännellen, jotta liuos leviäisi tasaisesti rehuun. Säilöntäainetta annosteltiin suosituksen mukaan niin, että säilöntäainetta tuli suhteessa viisi litraa rehutonnia kohti. Rehut tiivistettiin siiloihin käsin. Yhden minisiilon rehumäärän painotavoite oli 95 grammaa, joka määritettiin puhtaalla (100/0) timoteinurmisilpulla. Tavoitteena oli, että siiloihin jäisi mahdollisimman vähän ilmaa.

Siilot säilytettiin pimeässä tasalämpöisessä paikassa koko säilönnän ajan. Säilönnän aikana seurattiin minisiilojen säilöntälämpötilaa päivittäin, sekä kaasun ja puristenesteen muodostusta kaasun muodostuksen intensiteetin mukaan. Siilojen sulkemisen jälkeen niissä syntyneet kaasut ja puristenesteet poistettiin ja mitattiin säännöllisesti kaasun- ja puristenesteen muodostumisen mukaan injektioruiskun avulla. Minisiilot avattiin 90 säilöntäpäivän jälkeen 14.9.2010. Rehut punnittiin, painohävikki laskettiin ja näytteet pakastettiin.

Timotein ja voikukan raaka-ainenäytteet ja säilörehunäytteet analysoitiin MTT Kotieläintuotannon tutkimuksen laboratoriossa. Timoteistä ja voikukasta oli yhdet raaka-ainenäytteet. Niistä analysoitiin primäärinen ja sekundäärinen kuiva-aine pitoisuus, tuhka ja raakavalkuainen, puskurikapasiteetti, kivennäispitoisuudet $(\mathrm{Ca}, \mathrm{Mg}, \mathrm{P}, \mathrm{S}, \mathrm{K}$ ja $\mathrm{Na}$ ), hivenaineet ( $\mathrm{Fe}, \mathrm{Cu}, \mathrm{Zn}$ ja $\mathrm{Mn}$ ), orgaanisen aineen sellulaasiliukoisuus ja NDF. Säilörehunäytteitä oli yhteensä 15 . Niistä analysoitiin primäärinen ja sekundäärinen kuiva-ainepitoisuus, tuhka, pH, VFA:t (etikka-, propioni-, isovoi-, voi-, isovaleriaana-, valeriaana- ja kapronihappo), maitohapon, sokerin, ammoniumtypen ja liukoisen typen määrät, orgaanisen aineen sellulaasiliukoisuus ja NDF. Myös säilörehunäytteistä analysoitiin samat kivennäiset ja hivenaineet kuin raaka-ainenäytteistä. Tulokset laskettiin SAS 9.2 ohjelmistolla EG:n 4.2. versiota käyttäen. Rehuarvot ja säilöntälaatuparametrit laskettiin Mixed-proseduurilla siten, että voikukan osuus oli kiinteä tekijä ja toisto satunnainen tekijä. Parivertailut tehtiin Tukey-Kramerin testillä. Puristenesteiden laskennassa käytettiin Friedmanin testiä.

\section{Tulokset ja tulosten tarkastelu}

\section{Säilörehun kemiallinen koostumus ja rehuarvot}

Rikkakasvien torjuntaa nurmista perustellaan muun muassa säilörehun rehuarvon heikkenemisellä verrattuna rikkakasvittomiin rehuihin. Nyt tehdyssä kokeessa D-arvo oli puhtaassa voikukkasäilörehussa $27 \mathrm{~g} / \mathrm{kg}$ ka matalampi kuin timoteisäilörehussa (Taulukko 1). Pellolla pieni määrä voikukkaa ei välttämättä juurikaan vaikuta säilörehun $D$-arvoon, koska käytännössä ja tässä kokeessa voikukan osuus rehusta lasketaan tuorepainosuhteena. Tämän kokeen ja Isselteinin (1993) mukaan voikukka ei juuri vaikuta säilörehun sulavuuteen ja energia-arvoon, vaikkakin kirjallisuudesta löytyy myös vastakkaisia tuloksia (Mainz 1995, Isseltein 1993). 
Taulukko 1. Voikukan vaikutus säilörehun rehuarvoihin, kemialliseen koostumukseen ja säilöntälaatuun.

\begin{tabular}{|c|c|c|c|c|c|c|c|}
\hline & $\begin{array}{c}0 \% \\
\text { voikukkaa }\end{array}$ & $\begin{array}{c}25 \% \\
\text { voikukkaa }\end{array}$ & $\begin{array}{c}50 \% \\
\text { voikukkaa }\end{array}$ & $\begin{array}{c}75 \% \\
\text { voikukkaa } \\
\end{array}$ & $\begin{array}{c}100 \% \\
\text { voikukkaa }\end{array}$ & SEM & P-arvo \\
\hline Kuiva-aine g/kg & $334 \mathrm{a}$ & $292 b$ & $247 \mathrm{c}$ & $204 d$ & $167 \mathrm{e}$ & 3,7 & $* * *$ \\
\hline Muuntokelpoinen & & & & & & & \\
\hline energia $\mathrm{MJ} / \mathrm{kg} \mathrm{ka}$ & $11,3 \mathrm{a}$ & $11,3 \mathrm{ab}$ & $11,2 \mathrm{ab}$ & $11,1 \mathrm{~b}$ & $11,8 \mathrm{c}$ & 0,05 & $* * *$ \\
\hline $\mathrm{pH}$ & 3,94 & 3,87 & 3,84 & 3,84 & 3,88 & 0,051 & \\
\hline \multicolumn{8}{|l|}{ Kuiva-aineessa g/kg ka } \\
\hline D-arvo & $704 \mathrm{a}$ & $703 \mathrm{ab}$ & $701 \mathrm{ab}$ & $694 b$ & $677 c$ & 2,8 & $* * *$ \\
\hline Raakavalkuainen & $106 \mathrm{a}$ & $105 \mathrm{a}$ & $110 \mathrm{a}$ & $116 \mathrm{a}$ & $132 \mathrm{~b}$ & 3,7 & $* * *$ \\
\hline OIV & 85,7 & 85,4 & 86,1 & 86,3 & 87,2 & 0,70 & \\
\hline PVT & $-16,7 \mathrm{ab}$ & $-17,6$ a & $-12,7 \mathrm{ab}$ & $-7,0 \mathrm{~b}$ & $9,1 \mathrm{c}$ & 3,12 & $* *$ \\
\hline NDF & $557 \mathrm{a}$ & $535 \mathrm{a}$ & $482 \mathrm{~b}$ & $431 \mathrm{c}$ & $310 \mathrm{~d}$ & 9,5 & $* * *$ \\
\hline Tuhka & $61,2 \mathrm{a}$ & $69,6 \mathrm{~b}$ & $82,0 \mathrm{c}$ & $96,6 \mathrm{~d}$ & $122,0 \mathrm{e}$ & 1,35 & $* * *$ \\
\hline Sokeri & 102,4 & 66,7 & 60,0 & 18,9 & 60,0 & 24,85 & \\
\hline VFA (yhteensä) & 15,6 & 17,5 & 18,4 & 21,4 & 17,4 & 2,20 & \\
\hline Voihappo & 0,18 & 0,13 & 0,12 & 0,11 & 0,10 & 0,033 & \\
\hline Etikkahappo & 15,3 & 17,3 & 18,2 & 21,2 & 17,2 & 2,22 & \\
\hline Maito- ja muurahaishappo & $29,7 \mathrm{a}$ & $53,9 \mathrm{ab}$ & $61,9 \mathrm{~b}$ & $77,6 \mathrm{~b}$ & $83,9 \mathrm{~b}$ & 9,94 & $*$ \\
\hline Ammonium $\mathrm{N} g / \mathrm{kg} \mathrm{N}$ & $41,7 \mathrm{a}$ & $53,0 \mathrm{~cd}$ & $55,3 \mathrm{~d}$ & $45,1 \mathrm{ab}$ & $49,1 \mathrm{bc}$ & 2,60 & $* *$ \\
\hline Liukoinen $\mathrm{N}$ g/kg N & $779 \mathrm{a}$ & $742 \mathrm{a}$ & $653 \mathrm{~b}$ & $563 c$ & $432 \mathrm{~d}$ & 22,3 & $* * *$ \\
\hline Kalsium & $2,05 \mathrm{a}$ & $2,69 \mathrm{~b}$ & $3,61 \mathrm{c}$ & $4,87 \mathrm{~d}$ & $7,28 \mathrm{e}$ & 0,170 & $* * *$ \\
\hline Magnesium & $0,77 \mathrm{a}$ & $1,00 \mathrm{~b}$ & $1,34 \mathrm{c}$ & $1,66 \mathrm{~d}$ & $2,48 \mathrm{e}$ & 0,071 & $* * *$ \\
\hline Kalium & 23,9 a & $27,4 \mathrm{~b}$ & $32,5 \mathrm{c}$ & $37,1 \mathrm{~d}$ & $47,5 \mathrm{e}$ & 0,62 & $* * *$ \\
\hline Fosfori & $2,74 \mathrm{a}$ & $2,86 \mathrm{ab}$ & $3,04 \mathrm{~b}$ & $3,02 \mathrm{~b}$ & $3,52 \mathrm{c}$ & 0,071 & $* * *$ \\
\hline
\end{tabular}

$\mathrm{SEM}=$ keskiarvon keskivirhe. $* * *=\mathrm{P}<0,001, * *=\mathrm{P}<0,01, *=\mathrm{P}<0,05, \mathrm{O}=\mathrm{P}<0,10$. Saman rivin luvut eroavat toisistaan, jos ne on merkitty eri kirjaimella (Tukey-Kramerin testi).

Timotei- ja voikukkasäilörehun raakavalkuaispitoisuuden ero oli vain $26 \mathrm{~g} / \mathrm{kg}$ ka (Taulukko 1). Tässä kokeessa timoteisäilörehun raakavalkuaispitoisuus oli erittäin matala (106 g/kg ka).

Aiemmissa kokeissa voikukan raakavalkuaispitoisuus on ollut 97-303 g/kg ka välillä (Harrington ym. 2006, Issel-stein 1993, Isselstein \& Daniel 1996, Wyss \& Vogel 1994). Erilaiset koejärjestelyt, kuten niittoaika ja typpilannoituksen taso ovat vaikuttaneet voikukan raakavalkuaispitoisuuksiin. Voikukka säilörehun NDF-pitoisuus oli $247 \mathrm{~g} / \mathrm{kg}$ ka vähemmän kuin timoteisäilörehussa. Voikukan sisältämät NDF-pitoisuudet ovat heinäkasveja matalammat myös muiden kokeissa (Wyss \& Vogel 1994 ja Harrington ym. 2006). Harringtonin ja muiden kokeessa (2006) voikukan NDFpitoisuus oli $262 \mathrm{~g} / \mathrm{kg}$ ka ja eng-lanninraiheinän $281 \mathrm{~g} / \mathrm{kg}$ ka. Wyssin ja Vogelin kolmen niiton kokeessa (1994) NDF-pitoisuus vaihteli heinävaltaisessa kasvustossa $192 \mathrm{~g} / \mathrm{kg}$ ka (1. niitto), $272 \mathrm{~g} /$ kg ka (2.niitto) ja $207 \mathrm{~g} / \mathrm{kg}$ ka (3. niitto) välillä ja voikukkavaltaisessa kasvustossa $156 \mathrm{~g} / \mathrm{kg} \mathrm{ka} \mathrm{(1.}$ niitto), $218 \mathrm{~g} / \mathrm{kg} \mathrm{ka} \mathrm{(2.} \mathrm{niitto)} \mathrm{ja} 171 \mathrm{~g} / \mathrm{kg}$ ka. Veden säilöminen lisää säilörehun korjuukustannuksia, koska rehun kosteuspitoisuuden lisään-tyessä rehupaalien ja -kuormien lukumäärä lisääntyy. Lisäksi talvella rehun jäätyminen aiheuttaa haas- 
teita Suomessa. Voikukkapitoisen säilörehun yksi heikkous on sen matalampi kuiva-ainepitoisuus nurmiheiniin verrattuna. Koerehujen esikuivatuksen jälkeen voikukan kuiva-ainepitoisuus jäi matalammaksi ja olisi vaatinut pidemmän esikuivatusajan, jotta se olisi ollut yhtä kuivaa kuin timotei. Minisiilokokeen saman aikaa kuivatettujen voikukka- ja timoteirehujen kuiva-ainepitoisuusero oli 173 $\mathrm{g} / \mathrm{kg}$ ja valmiin säilörehun, josta oli poistunut puristenestettä, vastaava luku oli $167 \mathrm{~g} / \mathrm{kg}$. Voikukkapitoisuuden lisääntyminen lisäsi puristenesteen määrää (Taulukko 2), mikä on voinut lisätä kuivaainetappioita säilönnän aikana (McDonald ym. 1991), mutta tässä kokeessa puristenestettä syntyi runsaasti vasta, kun voikukan osuus oli $75 \%$ :a. Rehuilla, joita esikuivatetaan lyhemmän aikaa, voivat puristenestetappiot lisääntyä jo pienillä voikukkapitoisuuksilla. Tulosten perusteella voikukkapitoisen säilörehun esikuivatusaikaa on syytä pidentää voikukkapitoisuuden mukaan, jos mahdollista.

Taulukko 2. Säilönnän aikana kertyneen puristenesteen määrä

\begin{tabular}{cc}
\hline Koejäsen & $\begin{array}{c}\text { Puristeneste } \\
\text { ml/säilönnän aikana }\end{array}$ \\
\hline \hline $0 \%$ voikukkaa & 0,6 \\
$25 \%$ voikukkaa & 0,8 \\
$50 \%$ voikukkaa & 0,8 \\
$75 \%$ voikukkaa & 11,3 \\
$100 \%$ voikukkaa & 22,0 \\
\hline SEM & 2,25 \\
P-arvo & $*$ \\
\hline
\end{tabular}

$\mathrm{SEM}=$ keskiarvon keskivirhe. Suorat keskiarvot ja Friedmanin testin p-arvo. $*(\mathrm{P}<0,05)$.

Rikkakasvit sisältävät useimmiten enemmän tuhkaa kuin nurmikasvit (Wyss \& Vogel 1994, Harrington ym. 2006). Puhtaan voikukkasäilörehun kalsiumin, kalium ja magnesiumpitoisuudet ovat korkeammat verrattuna nurmisäilörehuun, mikä tukee Tauriaisen ja Ala-Kauppilan (2003), Harringtonin ym. (2006) tuloksia (Taulukko 3). Tässä kokeessa kivennäispitoisuudet lisääntyivät lineaarisesti voikukan määrän lisääntyessä säilörehussa. Puhtaassa voikukkasäilörehussa $\mathrm{K} /(\mathrm{Ca}+\mathrm{Mg})$ ekvivalenttisuhteeseen oli 2,1 verrattuna puhtaaseen nurmisäilörehuun, jossa se oli 3,6. Tavoitearvo on alle 2,2 (Pyörälä \& Tiihonen 2005). Näin ollen voikukkapitoisen säilörehun ekvivalenttisuhde on timoteita parempi. 
Taulukko 3. Voikukan ja nurmisäilörehun kivennäispitoisuuksia

\begin{tabular}{|c|c|c|c|c|c|c|c|c|c|}
\hline & \multicolumn{3}{|c|}{ Nurmirehu } & \multicolumn{6}{|c|}{ Voikukka } \\
\hline & $\begin{array}{l}\text { Nurmi- } \\
\text { säilörehu }\end{array}$ & $\begin{array}{c}\text { 1.sato D-arvo } \\
690 \mathrm{~g} / \mathrm{kg} \mathrm{ka}\end{array}$ & $\begin{array}{l}\text { Timotei- } \\
\text { heinä }\end{array}$ & $\begin{array}{l}\text { Voi- } \\
\text { kukka }\end{array}$ & 1.sato & 2.sato & kesäkuu & heinäkuu & elokuu \\
\hline & $\begin{array}{l}\text { Alasuutari } \\
\text { ym. (2010) }\end{array}$ & $\begin{array}{l}\text { MTT } 2010, \\
\text { rehutaulu- } \\
\text { kot }\end{array}$ & $\begin{array}{l}\text { Tauriai- } \\
\text { nen ja } \\
\text { Ala- } \\
\text { Kauppila } \\
\text { (2003) }\end{array}$ & $\begin{array}{l}\text { Harring- } \\
\text { ton ym. } \\
(2006)\end{array}$ & \multicolumn{2}{|c|}{$\begin{array}{l}\text { Virkajärvi \& } \\
\text { Punkki n.d. }\end{array}$} & \multicolumn{3}{|c|}{$\begin{array}{l}\text { Tauriainen \& Ala-Kauppila } \\
\text { (2003) }\end{array}$} \\
\hline & \multicolumn{3}{|c|}{$\mathrm{g} / \mathrm{kg} \mathrm{ka}$} & \multicolumn{6}{|c|}{$\mathrm{g} / \mathrm{kg} \mathrm{ka}$} \\
\hline $\mathrm{P}$ & $2,0-4,0$ & 3,2 & 2,2 & 5,7 & 3,4 & 3,9 & 3,8 & 3,4 & 5,5 \\
\hline $\mathrm{K}$ & $10-30$ & 31 & 30 & 34 & 51 & 54 & 52 & 52 & 64 \\
\hline $\mathrm{Ca}$ & $1,0-7,0$ & 3,8 & 3,0 & 9,6 & 13 & 15 & 8,7 & 10 & 13 \\
\hline $\mathrm{Mg}$ & $0,5-3,0$ & 1,7 & 1,2 & 3,5 & 2,8 & 3,5 & 3,3 & 3,1 & 5,2 \\
\hline $\mathrm{Na}$ & $0,0-0,5$ & 0,2 & 0,1 & 4,2 & 0,3 & 0,6 & 0,3 & 0,3 & 0,3 \\
\hline $\begin{array}{l}\mathrm{K} /(\mathrm{Ca}+\mathrm{Mg}) \\
\text { ekv.suhde }\end{array}$ & $<2,2^{*}$ & 2,4 & 3,1 & 1,1 & 1,5 & 1,3 & 1,9 & 1,8 & 1,5 \\
\hline
\end{tabular}

\section{Säilörehun säilönnällinen laatu}

Kaikki koerehut olivat hyvälaatuisia, kun niitä arvioitiin virhekäymishappojen perusteella. Voikukkasäilörehu oli säilynyt jopa paremmin kuin timoteisäilörehu, kun verrataan säilörehujen liukoisen typen määrää typen kokonaismäärästä (Taulukko 1). Kasvin puskurikyky eli puskurikapasiteetti kuvaa sen kykyä vastustaa pH:n muutosta ja pH:n laskua estävien ainesosien eli anionien määrää. Aikaisemmissa kokeissa nurmikasvien puskurikapasiteetti on ollut pienempi kuin palkokasvien ja voikukan (Nurmirehujen tuotanto ja käyttö 2010, McDonald 1991). Nyt tehdyn kokeen raaka-ainenäytteissä voikukan puskurikapasiteetti oli 526 mekv/kg ka ja timotein 279 mekv/kg ka. Isselteinin ja Danielin (1996) kokeessa voikukan puskurikapasiteetti on ollut vieläkin korkeampi (632-654 mekv/kg ka), joka on riippunut voikukan kehitysasteesta. Timotein puskurikapasiteetti on ollut välillä $188-342 \mathrm{mekv} / \mathrm{kg}$ ka (McDonald ym. 1991). Minisiilokokeessa voikukan määrä ei vaikuttanut säilörehun $\mathrm{pH}$ :hon eikä sokereiden määrään. Kaikissa säilörehuissa $\mathrm{pH}$ oli alle 4 ja sokereita oli jäljellä numeroarvoisesti hyvän säilörehun suositusten mukaisesti (Artturi®-verkkopalvelu 2011) lukuun ottamatta säilörehua, jossa oli $75 \%$ :a voikukkaa. Näin ollen voidaan olettaa, että rehuissa on ollut riittävästi sokereita käymisreaktioon. Tulosten perusteella voidaan todeta, ettei puskurikapasiteetti vaikuttanut säilörehun säilöntälaatuun, mitä tukee Isselsteinin ja Danielin (1993, 1996) sekä Wyssin ja Vogelin (1994) kokeiden tulokset.

Haihtuvien rasvahappojen yhteismäärä oli samanlainen voikukan määrästä riippumatta ja suurin osa hapoista oli etikkahappoa. Virhekäymishappojen määrät olivat kaikissa rehuissa kuitenkin pieniä Taulukko 1). Aikaisemmissa kokeissa huomattiin myös, että voikukkaa sisältävässä säilörehussa käy-misreaktiot olivat nopeampia tai intensiivisempiä kuin nurmisäilörehuissa ja sen takia säilörehun pH laski nopeammin (Isseltein \& Daniel 1993, 1996, Wyss \& Wogel 1994). Tässä kokeessa voikukalla ei ollut merkittävää vaikutusta siilossa syntyneeseen kaasujen yhteismäärään (parvo $=0,9)$. Säilörehun maito- ja muurahaishapon määrä lisääntyivät, kun voikukan osuus säilörehussa lisääntyi. Ero ei kui-tenkaan ollut merkitsevä muuta kuin siirryttäessä puhtaasta timoteisäilörehusta säilörehuun, jossa oli $25 \%$ :a voikukkaa.

Ammoniumtypen määrä kokonaistypestä muuttui ristiriitaisesti, kun voikukan määrä muuttui. Kaikissa säilörehuissa sen osuus oli kuitenkin maltillinen (alle $56 \mathrm{~g} / \mathrm{kg} \mathrm{ka}$ ) eli valkuainen ei ollut ha-jonnut kovin pitkälle. Voikukkasäilörehussa liukoisen typen määrä (432 g/kg N) oli selvästi matalampi kuin timoteisäilörehussa $(779 \mathrm{~g} / \mathrm{kg} \mathrm{N})$ ja määrä pieneni melko lineaarisesti, kun voikukkapitoisuus 
lisääntyi. Timoteipitoisen säilörehun osalta liukoisen typen määrä oli suhteellisen suuri ( $779 \mathrm{~g} / \mathrm{kg} \mathrm{N})$, joka viittasi mahdolliseen virhekäymiseen.

Tulokset antavat viitteitä, että vastoin yleisiä oletuksia voikukkasäilörehu oli säilynyt hyvin ja valkuaisen hajoaminen oli jäänyt vähäiseksi. Tulokset viittaavat siihen, että voikukka ei vaikuttanut heikentävästi säilörehun säilönnälliseen laatuun, mikä on linjassa kirjallisuuden tulosten kanssa (Isselstein \& Daniel 1993, 1996, Wyss \& Vogel 1994). Voikukkasäilörehu edellyttää kuitenkin hyviä säilöntäolosuhteita, kuten riittävää määrää sokereita (Wyss \& Vogel 1994) ja maitohappokäymistä, jotta pH laskee riittävän alas korkeasta puskurikapasiteetista huolimatta.

\section{Johtopäätökset}

Voikukan matala kuiva-ainepitoisuus voi lisätä puristenestetappioita erityisesti, jos voikukkapitoisuus on suuri ja jos voikukkapitoisen säilörehun esikuivatusaikaa ei pidennetä puhtaaseen nurmisäilörehuun verrattuna. Voikukkapitoisen säilörehun D-arvo oli vain $27 \mathrm{~g} / \mathrm{kg}$ ka pienempi kuin timoteisäilörehun. Näin ollen pienillä voikukkapitoisuuksilla ei välttämättä ole vaikutusta säilörehun sulavuuteen. Raakavalkuainen sitä vastoin oli $26 \mathrm{~g} / \mathrm{kg}$ ka pienempi voikukkasäilörehussa verrattuna timoteisäilörehuun. Voikukan rehuarvoihin ja kemialliseen koostumukseen vaikuttavat paljon koeolosuhteet kuten typpilannoituksen määrä ja niittoaika. Voikukassa on timoteitä enemmän kaliumia, mutta myös enemmän kalsiumia ja magnesiumia. Ekvivalenttisuhteena laskettuna kaliumin määrä suhteessa kalsiumin ja magnesiumin yhteismäärään oli suositusten mukainen sekä tämän kokeen, että kirjallisuuden perusteella.

Tämän kokeen ja kirjallisuuden perusteella voidaan olettaa, että voikukkapitoisesta nurmesta voidaan saada säilöntälaadultaan laadukasta rehua, ja ettei voikukan nurmea korkeampi puskurikapasiteetti ole ongelma etenkään, jos säilönnän onnistumisen muut edellytykset ovat kunnossa.

\section{Kirjallisuus}

Alasuutari, S., Manni, K. \& Rautala, H. 2010. Lypsylehmän ruokinta ja hoito. 3. tark. p. Opetushallitus. Vantaa: Juvenesprint.

Artturi®-verkkopalvelu. 2011. Säilönnällinen laatu. Viitattu 30.11.2011.

https://portal.mtt.fi/portal/page/portal/Artturi.

Huhtamäki, T. 2011. Suullinen tiedonanto.

Harrington, K. C., Thatcher, A. \& Kemp, P. D. 2006. Mineral Composition and Nutritive Value of Some Common Pasture Weeds. New Zealand Plant Protection 59: 261-265 s.

Isselstein, J. 1993. Forage nutritive value and ensilability of some common grassland herbs. Proceedings of the XVII International Grassland Congress 1993: 557-579 s.

Isselstein, J. \& Daniel, P. 1996. Eds. Parente, G., Frame, J. \& Orsi, S. The Ensilability of Grassland Forbs. Grassland and Land use systems 16th EGF Meeting 1996: 451-455 s.

Kajan, T. \& Nousiainen, J. 2006. Rikkakasvitorjunnan vaikutus säilörehunurmen rehuyksikkösatoon. Opinnäytetyö, Savonia-ammattikorkeakoulu.

Mainz, A. K. 1995. Futterqualitat und Konservierungseigenschaften verbreiteter Grunlandkrauter. JustusLiebig-Universitat, Giessen, Germany.

McDonald, P., Henderson, A. R. \& Heron, S. J. E. 1991. The Biochemistry of Silage. 2nd ed. Aberystwyth: Chalcombe.

Pyörälä, S. \& Tiihonen, T. 2005. Magnesiumin saantiin liittyvät häiriöt. Viitattu 1.11.2010.

http://ethesis.helsinki.fi/julkaisut/ela/sarjat/oppimateriaalia/6/03_magnesiumin_saantiin_liittyvat_hairiot.pdf.

Rehutaulukot. 2010. Viitattu 30.11.2011. https://portal.mtt.fi/portal/page/portal/Rehutaulukot.

Tauriainen, S. \& Ala-Kauppila, A. 2003. Nurmen kuokkavieraat uhkaavat kivennäistasapainoa. KMVET 7: 24-25 s.

Tike. 2011a. Kotieläinten lukumäärä. Matilda maataloustilastot. Viitattu 15.11.2011. http://www.maataloustilastot.fi/tilasto/36, Kotieläintuotanto, Kotieläinten lukumäärät.

Tike. 2011b. Käytössä oleva maatalousmaa vuonna 2011 - ennakkotiedot 21.6.2011. Matilda maataloustilastot. Viitattu 15.11.2011. http://www.maataloustilastot.fi/kaytossa-oleva-maatalousmaa, Peltokasvituotanto, Käytössä oleva maatalousmaa, Käytössä oleva maatalousmaa vuonna 2011 -ennakkotiedot 21.6.2011.

Virkajärvi, P. \& Punkki, P. n.d. Säilörehunurmien rikkakasvien torjuntakokeiden tuloksia. Pohjois-Savon nurmiopas, 28-30 s.

Wyss, U. \& Vogel, R. 1994. Influence of Botanical Composition and Stage of Maturity of Forage on Fermentation Quality and In-silo Losses. 